\title{
Endoprosthetic insertion for malignant obstructive jaundice: A retrospective review
}

\author{
KENNETH P. TARR, DO \\ JOSEPH C. ANDREWS, DO \\ LOUIS G. PUTZ, DO \\ PETER J. MOORTON, DO \\ DAVID F. KARIBO, DO \\ JONATHAN L. GOLDSMITH, DO
}

We reviewed 13 cases of biliary endoprosthetic insertion for malignant obstructive jaundice from August 1983 to May 1987, and recorded (1) location and etiology of the obstruction, (2) length of time the endoprosthesis remained functional, and (3) complications related to the endoprosthesis, its insertion, or its long-term function.

Of the 13 patients, 3 had pancreatic carcinoma, 3 had cholangiocarcinoma, and 3 had metastatic disease to the porta hepatis. The underlying malignancy was not histologically proved in four patients despite evidence of neoplasm by percutaneous cholangiography and computerized tomography. These four patients were not

\footnotetext{
From the department of diagnostic radiology, Detroit Osteopathic Hospital/Bi-County Community Hospital, Warren, Mich, where, at the time this paper was written, Dr Tarr was senior resident; Dr Andrews, department chairman; and Drs Putz, Moorton, Karibo, and Goldsmith, staff radiologists. Dr Tarr is currently staff radiologist at Pontiac (Mich) Osteopathic Hospital and Lapeer (Mich) Regional Hospital.
}

Reprint requests to Kenneth P. Tarr, DO, department of radiology, Pontiac Osteopathic Hospital, 50 N Perry St, Pontiac, MI 48058. considered good surgical risks and were referred for percutaneous therapy.

The longest endoprosthetic patency was 3.5 years. Three patients experienced obstruction of the endoprosthesis at 3,4 , and 9 months after insertion, respectively. Two of the endoprostheses were subsequently removed endoscopically, while the third was extracted through a new percutaneous tract with use of a balloon angioplasty catheter.

Complications related to endoprosthetic insertion included bilous hydro pneumothorax (1 patient), subcutaneous and subcapsular liver abscess (1 patient), postinsertion cholangitis (4 patients), and reflex ileus (1 patient).

Malignant obstructive jaundice is a clinical entity for which interventional radiologic techniques have provided palliative nonsurgical therapy. Reports of these techniques first appeared in the literature in $1974^{1}$ documenting cases in which the obstructed biliary system could be consistently and safely entered and drained with use of percutaneous methods. These early reports described decompression and drainage through an indwelling external 
catheter that was placed across the obstruction for the reestablishment of the normal internal flow pattern of the bile.

Refinement in these techniques and the related equipment progressed rapidly from 1978 to $1983 .^{2-11}$ During this period, researchers also addressed the problem of the external drainage catheter. The catheter not only was a constant reminder of the patient's disease, but it also posed problems of dislodgement, pain, and infection at the insertion site, and limited daily activities.

It was thought that internal stenting of malignant obstructing lesions with use of a permanent endoprosthesis ideally could restore normal bile flow, thus preventing the development of malabsorption and dehydration. At the same time, no external catheter would be present, thus diminishing psychological side effects. More importantly, the internal stent would provide the potential for near normal daily and social activities such as showering, bathing, and swimming.

Unfortunately, internal stents produced new problems that necessitated removal, such as obstruction, migration, marked pain during insertion of the relatively large-bore stents, and high radiation exposures to the patient as well as the operator. These problems emphasized the need for physicians who perform internal biliary stenting to evaluate prospective patients critically, particularly with regard to future quality of life. The patient's present condition might not warrant the pain and possible complications inherent to the procedure.

Malignant biliary obstruction commonly occurs from pancreatic carcinoma, bile duct carcinoma (cholangiocarcinoma), and metastatic carcinoma to the liver, gallbladder, and bile ducts. According to 1987 statistics, cancer is the second leading cause of death after heart disease. ${ }^{12}$ Pancreatic carcinoma accounts for $3 \%$ of the cases of cancer of all sites. There is no apparent predilection for gender.

Despite what appears to be a low incidence, carcinoma of the pancreas offers one of the most dismal 5-year survival rates. ${ }^{12}$ These figures have changed little, even with the con- tinued advances in diagnostic imaging (ultrasound, computed tomography, and magnetic resonance imaging). The problem still remains in recognizing the early and relatively nonspecific signs that may alert a clinician to an underlying neoplastic process. Pancreatic carcinoma is commonly advanced at the time of diagnosis, with jaundice often being the initial symptom. Anorexia and weight loss also may be associated.

When combined, cancer of the liver and biliary ducts accounts for $2.0 \%$ and $2.3 \%$ of male and female cancer deaths for all sites, respectively. ${ }^{12}$ By itself, cancer of the extrahepatic bile ducts is $25 \%$ as common as pancreatic carcinoma. ${ }^{12}$ Affected patients also face grim 5-year survival rates, because they often do not show clinical signs until their obstruction is nearly complete. Bile is quite viscid and usually drains past partially obstructing lesions. The findings at cholangiography often disclose complete obstruction, but after a period of decompression a small tract through the lesion may be demonstrated. This initial obstruction is thought to be due to edema of the mucosa in the region of narrowing that causes an acute and complete obstruction, which subsequently subsides after drainage.

Small periampullary lesions often are the only cancers that offer the potential for complete surgical cure by pancreaticoduodenectomy (Whipple procedure). Primary carcinomas elsewhere in the biliary system, such as in the hepatic ducts, usually show extension into the liver at the time of diagnosis. Surgical resection for cure is then contraindicated. Five-year survival rates of resectable periampullary lesions treated by pancreaticoduodenectomy ranges from $8 \%$ to $28 \% .{ }^{13}$ Most patients, however, have distant metastasis at the time of diagnosis and generally die within 1 year. The median survival of patients with surgically unresectable lesions is 5 months. ${ }^{13}$

\section{Anatomy}

Anatomic relationships of importance in internal biliary stenting are illustrated in Figures $1^{14}$ and $2 .{ }^{15}$ Care is taken to keep the puncture site at or below the interspace of the tenth 


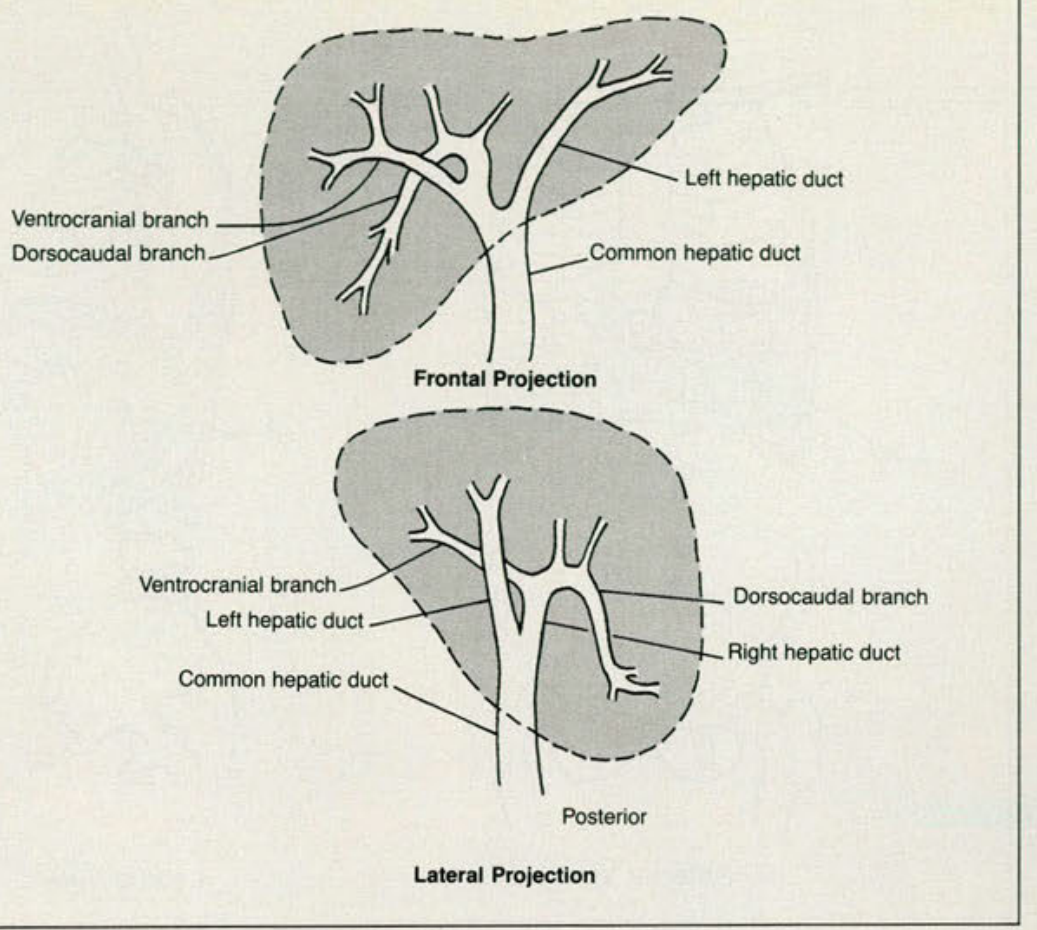

Figure 1. Drawings show the most common configuration of the intrahepatic ductal system. A minor degree of normal variation can be expected. (Modified from Schein et al. ${ }^{14}$ ) rib to avoid transgressing the pleura in the right costophrenic angle region. Occasionally, the actual site of puncture must be adjusted according to the individual's body habitus. Also, the puncture site must not be too low to jeopardize the surrounding abdominal viscera (ie, gallbladder, duodenum, or hepatic flexure of the colon). The entire course of the tube tract must remain within the parenchyma of the liver or the risk of bile leakage and hemorrhage increases.

Entrance most commonly takes place through the right dorsocaudal branch (Fig 1). ${ }^{14}$ Minor variations in ductal anatomy, as viewed on the cholangiographic films will dictate the optimal approach. If obstruction at the porta hepatis segregates the left hepatic duct from the main biliary tree, an anterior or subxiphoid approach will be necessary to drain this portion of the system (Fig 2) ${ }^{8,15}$ Which duct will be chosen for stent placement depends on whether or not enough duct is proximal to the obstruction to accommodate the stent and potential minor positional changes without its becoming obstructed or dislodged. Furthermore, the straighter and more horizon- tal the tract lies, the easier and less traumatic dilation and stent insertion will be.

\section{Patients and methods}

During the 44-month period from August 1983 to May 1987, a total of 24 patients ( 15 women and $9 \mathrm{men}$ ) were referred to the radiology department for evaluation and eventual intervention for obstructive jaundice. The patients ranged in age from 59 to 85 years. Of the 24 patients, 13 ( 7 women and 6 men) underwent percutaneous placement of an internal biliary endoprosthesis during a two-stage procedure. In the first part, percutaneous transhepatic cholangiography (PTC) and external catheter drainage were performed. Thereafter, endoprosthetic insertion was done. The main advantage of the staged approach is that it allows the byproducts of intervention (ie, blood clots, fibrin, bile, and debris) time to clear, precluding premature obstruction of the endoprosthesis.

All patients had a clinical history of anorexia, weight loss, and jaundice. Three patients also had concomitant biliary obstruction and cholangitis. Three others had a positive 
Figure 2. Anterior and left lateral views of the liver, intrahepatic bile ducts, and surrounding skeleton. A indicates the approach to the right tenth intercostal space; $\mathrm{B}$, the anterior approach (also subxiphoid). The smaller dot on the lateral view shows the puncture site at the skin, and the larger dot marks the entrance site into the biliary duct. (Modified from Netter. ${ }^{15}$ )
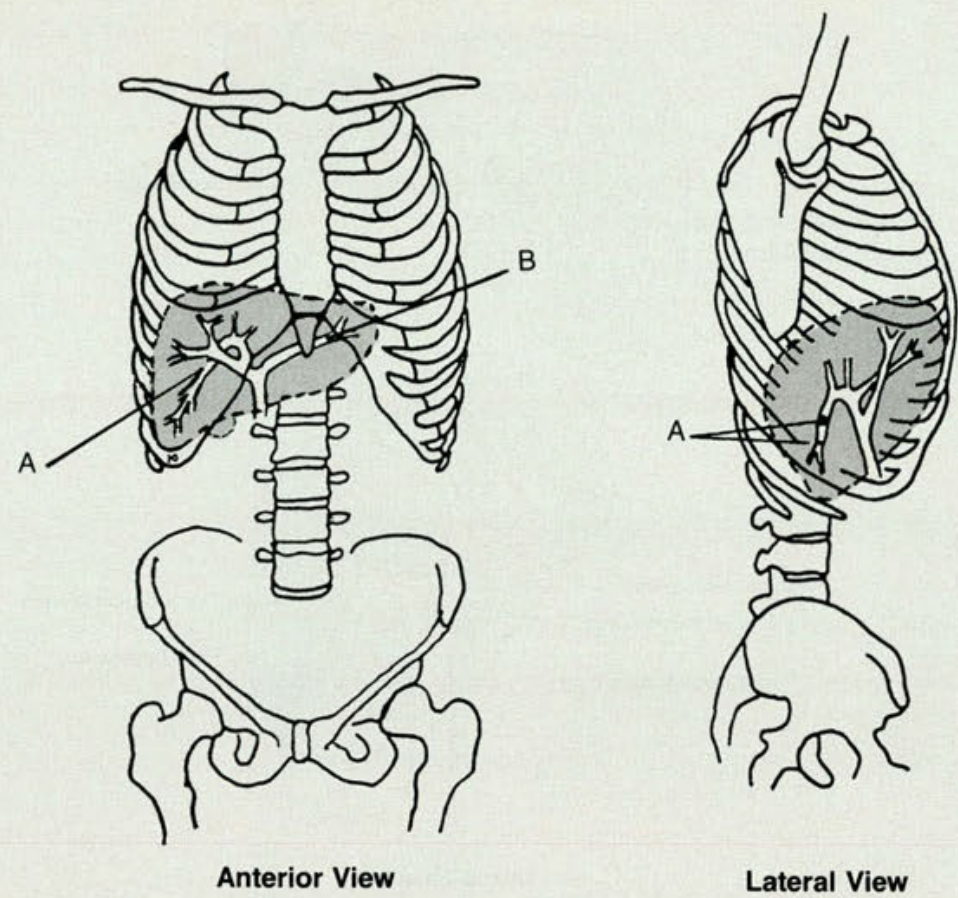

Lateral View history for metastasis from colon carcinoma (one patient) or gastric carcinoma (two patients). Results of liver function tests (alkaline phosphatase, lactic dehydrogenase, glutamic-pyruvic transaminase, and aspartate aminotransferase) were abnormal in all patients. Total bilirubin levels at admission ranged from 2.2 to $34.5 \mathrm{mg} / \mathrm{dL}$. Multimodality imaging (ultrasound, CT, and endoscopic retrograde cholangiopancreatography [ERCP]) and interventional techniques (PTC and needle biopsy) were used to define the location, extent, and cause of the obstruction.

Before PTC and external drainage were performed, consultation was given and informed consent was obtained from each patient. The following laboratory studies were evaluated: complete blood cell count, platelets, coagulation profile, and renal function tests. A broadspectrum cephalosporin was administered to each patient 12 to 24 hours before the procedure, and intravenous hydration was titrated to the individual's condition. An aminoglycoside was added if cholangitis was present.

The location and character of the obstruction were defined in all cases by PTC, and PTC was used to plan the approach for the drainage procedure. Installation of a C-arm fluoroscopy unit (General Electric) in the spring of 1985 greatly simplified the performance of the last five cases in this series. The new unit allowed the opacified biliary system to be viewed from all oblique as well as lateral angles, which facilitated entrance into the chosen duct with the least amount of punctures.

In two patients, the initial needle placement for PTC was satisfactory for catheter placement. A one-stick introducer system (MediTech No. OS2) then was used to place a 0.035 inch Bentson guidewire (Cook No. SFB35$135 \mathrm{BH})$ into the main biliary tree. If another biliary radical had to be entered, it was approached through the same skin incision with use of an 18-gauge diamond-tipped needle, as supplied in the Ring biliary drainage catheter set (Cook No. P8.3G-38-50-P32S-Ring). After the Bentson guidewire was placed, various angiographic catheters were used to negotiate the obstruction. If the maneuvering was successful, dilation and placement of the No. 8.3 French Ring external drainage catheter were done, and the procedure was terminated (Fig 
3). In six patients, the obstruction could not be traversed during the first stage, necessitating placement of a No. 8 French pigtail angiographic catheter, just above the area of blockage. This technique effectively drained the right and left main biliary systems. Thereafter, external gravity drainage was instituted, and the patient was returned to the hospital room.

External drainage was continued for at least 24 to 36 hours before another attempt was made at either negotiating the obstruction or inserting the endoprosthesis. All six patients successfully received the endoprosthesis on the second attempt, and external drainage was established for an additional 24 to 36 hours to help clear the bile.

Before the second stage, intravenous antibiotics, a sedative, an analgesic, and $0.6 \mathrm{mg}$ of intramuscular atropine were administered, as for the first procedure. A catheter cholangiogram was used to assess the function and placement of the drain and clearing of debris after the first stage.

We have used the Carey-Coons soft (MediTech No. CSS-12-15) endoprosthetic stent that is $20 \mathrm{~cm}$ long. The distal $5 \mathrm{~cm}$ of the stent is curved to lie within the duodenum. Large proximal and distal side holes help facilitate the passage of bile and debris. Attached to the proximal end is a nylon suture, which extends far enough from the tract to allow more proximal positioning of the stent, if necessary. The other end of the suture is attached to a small, round silastic "button," which anchors the stent when it is placed within the subcutaneous tissues at the site of insertion.

For the second stage, a 0.038 -inch Lunderquist-Ring torque-control wire (Cook No. HSF38-125-THG) is placed through the drainage catheter and curled within the duodenum. The drainage catheter is removed, and a No. 12 French dilator is "loaded" onto the guidewire. At this point, additional intravenous analgesic is administered before the dilation is passed through the lesions. This procedure may be quite painful, despite previous administration of intravenous medication.

The dilator is advanced with a slight clock- wise rotation to facilitate passage through the area of tumor. If the patient's discomfort is not too great, the dilator is left in place while the stent/stabilizer/straightener combination is assembled. The loaded stent is advanced into position after the dilator is removed. Usually enough residual contrast is present from the initial cholangiogram to guide the placement of the stent. Its position is adjusted so that the proximal end is just inside the ductal system but an adequate number of drainage holes are situated above the obstruction.

While the stent is stabilized, the central straightener is unlocked and removed. Care is taken not to remove the guidewire or change the position of the stent. Final positioning is

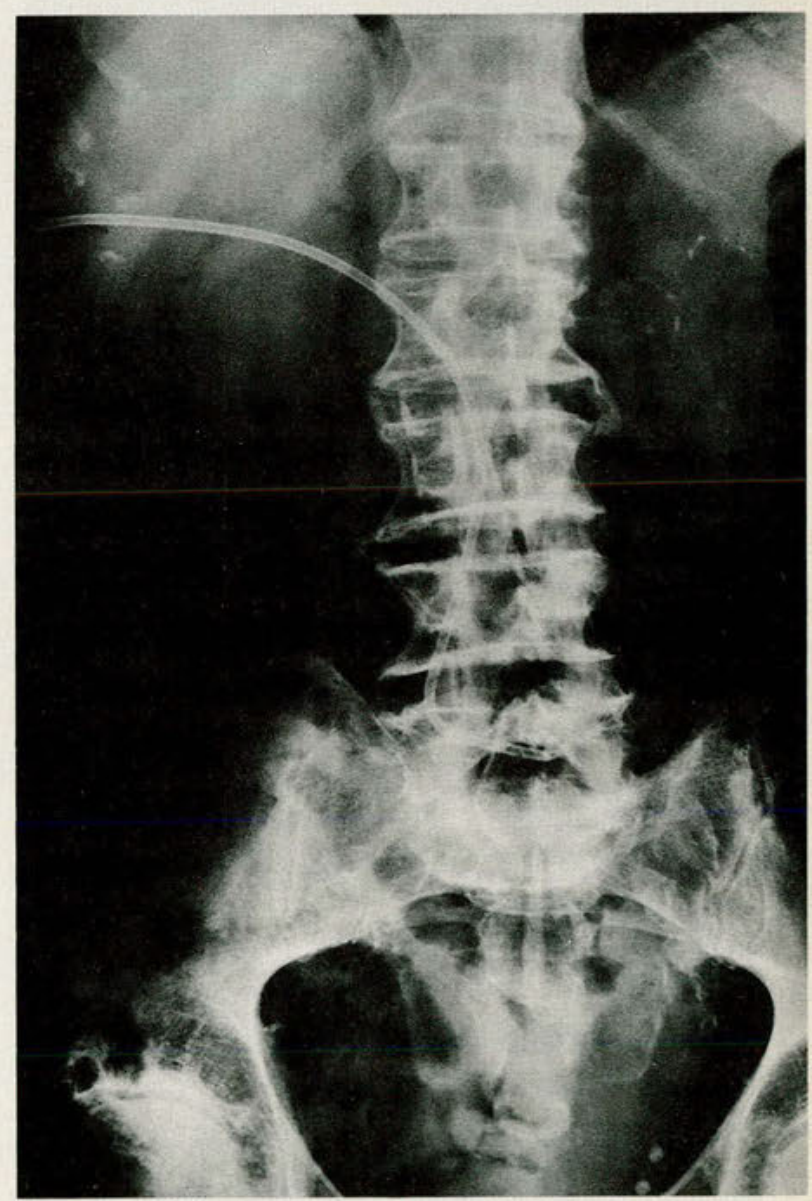

Figure 3. Plain abdominal roentgenogram taken the morning after the first step of the drainage procedure. The catheter has been placed past the obstruction; the distal pigtail tip is within the duodenum. Note prominent calcification of the splenic artery and degenerative disease of the spine. 


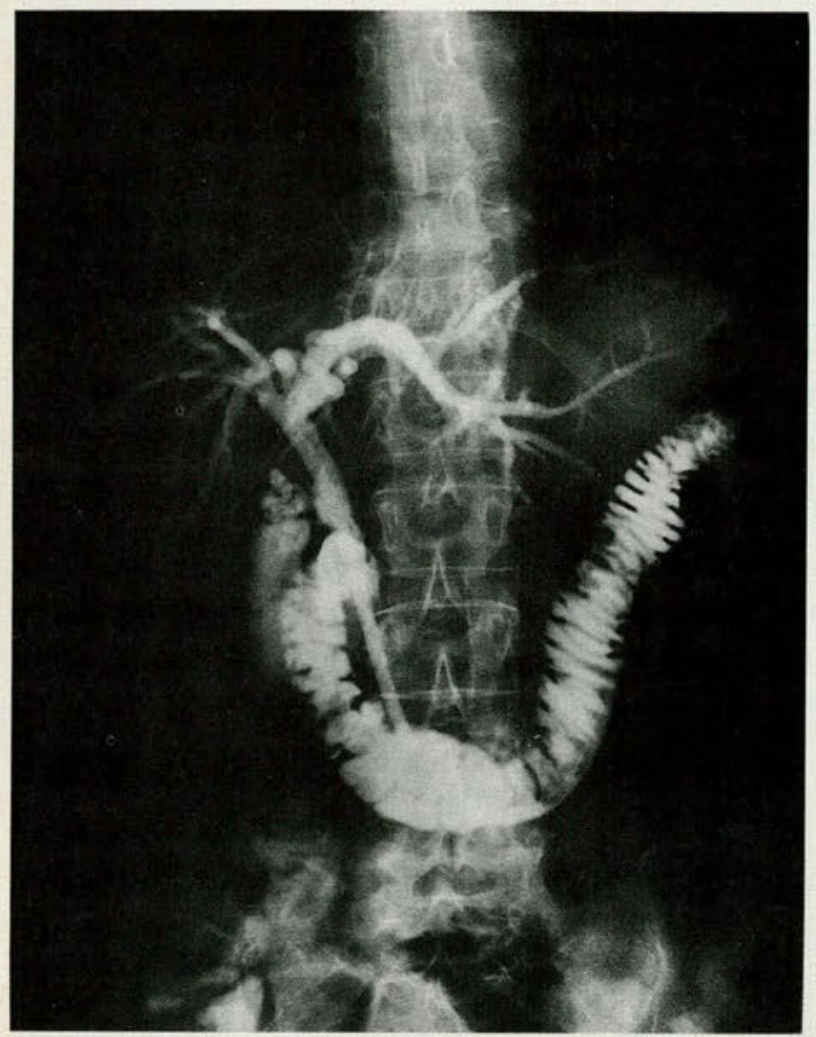

Figure 4. Postinsertion cholangiogram demonstrates excellent stent function, as contrast material appears equally in all areas of the biliary system. Essentially no debris lies in the ducts due to the relatively atraumatic insertion.

accomplished with use of the stabilizer and nylon suture. Next, the stabilizer is removed, the guidewire is placed through the center of the button, and the No. 7 French temporary external drainage catheter is advanced into the proximal end of the stent, with two to three drainage holes left within the main biliary system. The guidewire is carefully removed, and cholangiography through the external catheter is performed to assess positioning and function (Fig 4).

A subcutaneous "pocket" is then prepared by using minimal blunt dissection and strict sterile technique at the site of stent insertion. The button is placed within, and the nylon suture is tied to maintain tension on the stent and prevent distal migration. The skin edges are approximated with interrupted nylon sutures. The external drainage catheter is then fixed to the patient's side. Gravity drainage is instituted, and the catheter is gently flushed with 8 to $10 \mathrm{~mL}$ of sterile saline solution every 6 to 8 hours, until most of the byproducts of intervention have cleared.

A plain abdominal x-ray film is taken the following morning to assess the overall position of the stent. Usually cholangiography is performed on the second or third day to check patency and positioning. If the system is clear, the external catheter is capped with an injection port adapter (Deseret Med, Inc. No. 381255-1) and internal drainage is allowed to proceed until the following day. If the patient has tolerated this step (and does not have cholangitis or leakage from the insertion site), the external catheter is removed and a simple dressing is applied to the patient's side. Some drainage will persist for the next 24 to 48 hours, but will usually taper off rapidly thereafter.

Follow-up care usually includes intermittent abdominal films (Fig 5) to check the position of the stent. If needed, hepatobiliary scanning is used to assess stent functioning.

If catheter migration or obstruction occurs, the stent could be removed by two methods. The first is by endoscopy after the nylon fixating suture is severed. The other method, which also is done after the nylon fixating suture is severed, involves establishing a new percutaneous tract into the biliary system and cannulating the stent with a guidewire. The stent could then be removed by advancing a 4-mm angioplasty balloon dilatation catheter (MediTech No. DC/4-2/5/75) into the proximal end of the stent, inflating the balloon, thereby "locking" the stent and allowing fairly easy removal. Either a new stent could be inserted, or due to our patients' deteriorating condition, a Ring external and internal drainage catheter could be inserted.

\section{Results}

Patient results are summarized in Table 1 . Three patients are alive and are doing well to date. The first had gastric carcinoma metastatic to the porta hepatis. Two years after stent insertion, a total bilirubin level was 0.8 $\mathrm{mg} / \mathrm{dL}$. The second patient was suspected of 


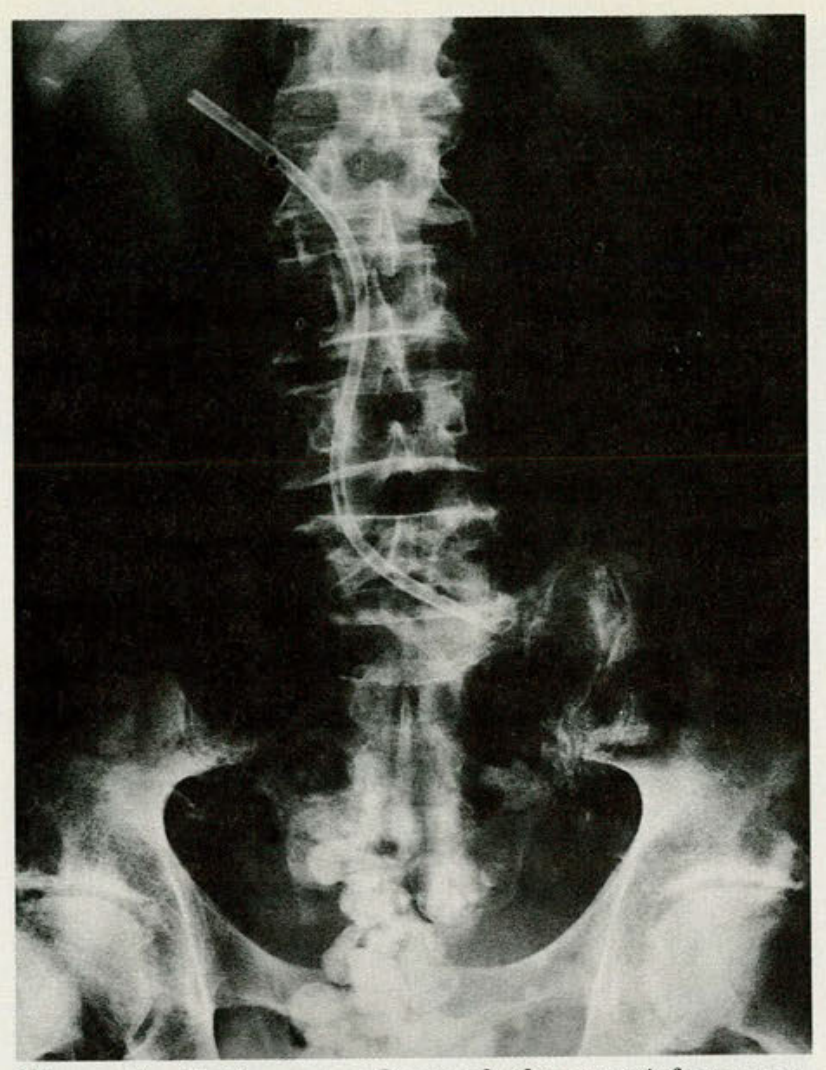

Figure 5. Follow-up radiograph shows satisfactory positioning of the stent. A comparison with postinsertion films disclosed no evidence of migration.

having pancreatic carcinoma, later confirmed by a biopsy. A total bilirubin level 6 months after stent insertion was $0.3 \mathrm{mg} / \mathrm{dL}$. Significant complications in this patient were a subcutaneous abscess at the insertion site and an abscess collection in the subcapsular area of the lateral liver at the tract entrance (Fig 6). These complications were recognized 1.5 weeks after the external catheter was removed.

The patient was readmitted to the hospital. After a 3-week course of intravenous antibiotics and three separate CT-guided aspirations of the abscess cavity, evidence of residual abscess was absent. A follow-up CT scan showed no recurrence 5 months later. Patient 3 was initially seen with cholangiocarcinoma of the distal common bile duct and underwent 7 months of internal drainage with an indwelling Ring catheter because of heavy debrisladen bile. He then had a poorly functioning catheter and requested an internal prosthesis.

\begin{tabular}{|c|c|c|}
\hline \multicolumn{3}{|c|}{$\begin{array}{l}\text { Table } 1 \\
\text { Causes of Obstruction and Results of } \\
\text { Endoprosthetic Insertion }\left(N=13^{*}\right)\end{array}$} \\
\hline \multicolumn{2}{|c|}{ Obstruction } & \multirow{2}{*}{$\begin{array}{l}\text { Duration } \\
\text { of stent } \\
\text { patency }\end{array}$} \\
\hline Cause & Level & \\
\hline $\begin{array}{l}\text { Pancreatic carcinoma } \\
\quad(\mathrm{n}=3)\end{array}$ & $\begin{array}{l}\text { Distal common } \\
\text { bile duct }\end{array}$ & 4-10 mo \\
\hline $\begin{array}{l}\text { Cholangiocarcinoma } \\
(\mathrm{n}=3)\end{array}$ & $\begin{array}{l}\text { Inferior to porta } \\
\text { hepatis }\end{array}$ & 1-9 mo \\
\hline $\begin{array}{l}\text { Metastatic carcinoma } \\
(\mathrm{n}=7) \\
\text { Gastric }(\mathrm{n}=2) \\
\text { Colon }(\mathrm{n}=1) \\
\text { Unproved }(\mathrm{n}=4)\end{array}$ & $\begin{array}{l}\text { Porta hepatis; } \\
\text { pancreatic } \\
\text { head }\end{array}$ & $2-3 \mathrm{wk}^{\dagger}$ \\
\hline
\end{tabular}

At 4 weeks after insertion, his total bilirubin level was $4.5 . \mathrm{mg} / \mathrm{dL}$.

Two of the patients who received internal stents were lost to follow-up. Of the eight patients who died, catheter patency ranged from 2 weeks to 3.5 years (mean, 21 weeks). The patient who survived 3.5 years with the original stent had no histologic documentation of malignancy in four separate biopsy procedures. She eventually showed CT evidence of tumor progression and had consistently elevated carcinoembryonic antigen levels $(100,158$, and $150 \mathrm{ng} / \mathrm{mL}$; normal for a nonsmoker is $<5.0$ $\mathrm{ng} / \mathrm{mL}$ ). This patient subsequently underwent radiation therapy and chemotherapy, with apparent remission of her malignancy. Approximately 3 months before her death due to a cerebrovascular accident, she had a 5-cm mass removed from the original stent insertion site (Fig 7). Pathologic evaluation showed metastatic mucin-secreting adenocarcinoma. An autopsy was declined by the family.

Three patients had their stents removed due to obstruction (two endoscopically and one percutaneously). All received a Ring external/ internal drainage catheter for the duration of their disease. Original endoprosthetic patency in this group was 3,4 , and 9 months, respectively.

Two patients had extremely short postinsertion courses: 2 and 3 weeks, respectively. Both had had advanced primary carcinomas: gastric and colon; multiple sites of metastasis in- 

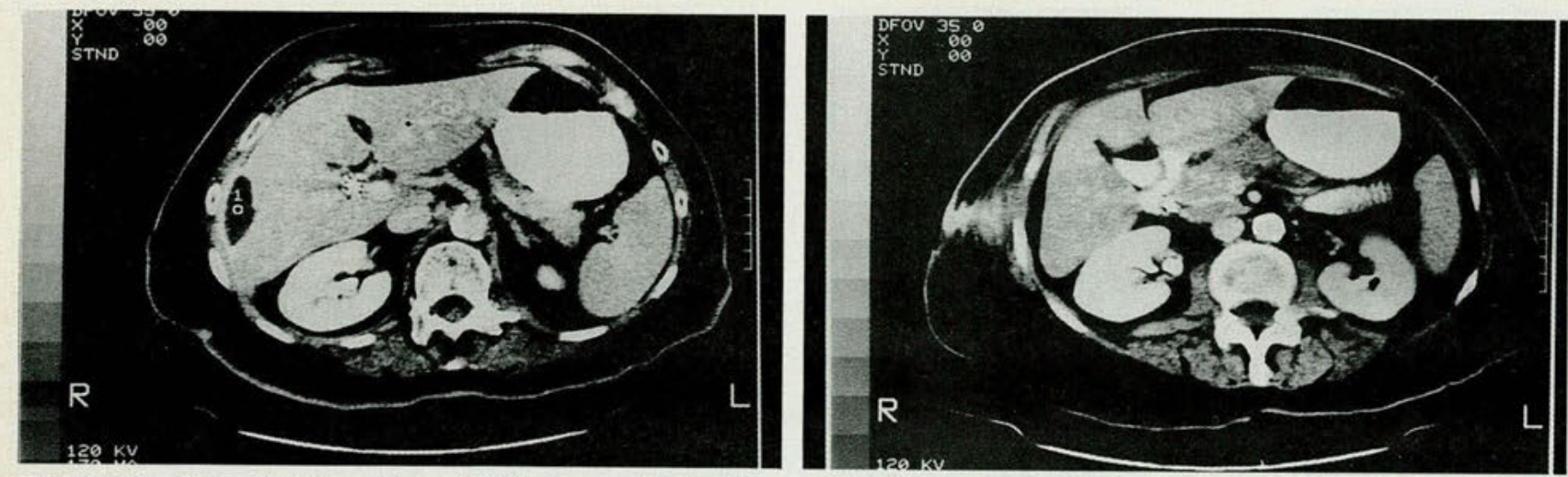

Figure 6. Top: Axial section of CT demonstrates lowdensity fluid collection, with an enhanced rim in the subcapsular area of the right lobe of the liver. Orally administered contrast material shows that the internal stent (arrow) is in the lumen. Evidence of stent obstruction and other areas of abscess collection are absent. Right: Axial section exhibits subcutaneous abscess/cellulitis along the insertion tract. No intraperitoneal fluid or thickening is observed.

cluded the bile ducts, porta hepatis, gallbladder, liver, pancreas, and surrounding nodal areas. The total bilirubin levels of both patients remained elevated, despite cholangiographic evidence of adequate drainage from both main biliary radicals.

One patient had an internal stent inserted into the left as well as the right biliary systems. She subsequently experienced catheter obstruction 9 months after insertion. The right stent was removed endoscopically and replaced with a Ring catheter. This patient did very well for the subsequent year before her death.

The most serious complication occurred in a 74-year-old man with advanced metastatic colon carcinoma. Plain x-ray films and CT scans showed advanced emphysematous changes of the lungs and a small, contracted liver (Fig 8). Due to the short craniocaudal dimension of his liver, puncture was performed in the ninth rib interspace to ensure that the drainage catheter would remain entirely within the liver parenchyma. On the third day after catheter insertion, bile-stained fluid was noticed from the puncture site during another attempted passage of the obstruction. Fluoroscopy and later plain upright radiographs of the chest (Fig 9) showed that the drainage catheter transgressed the pleura in the right costo-
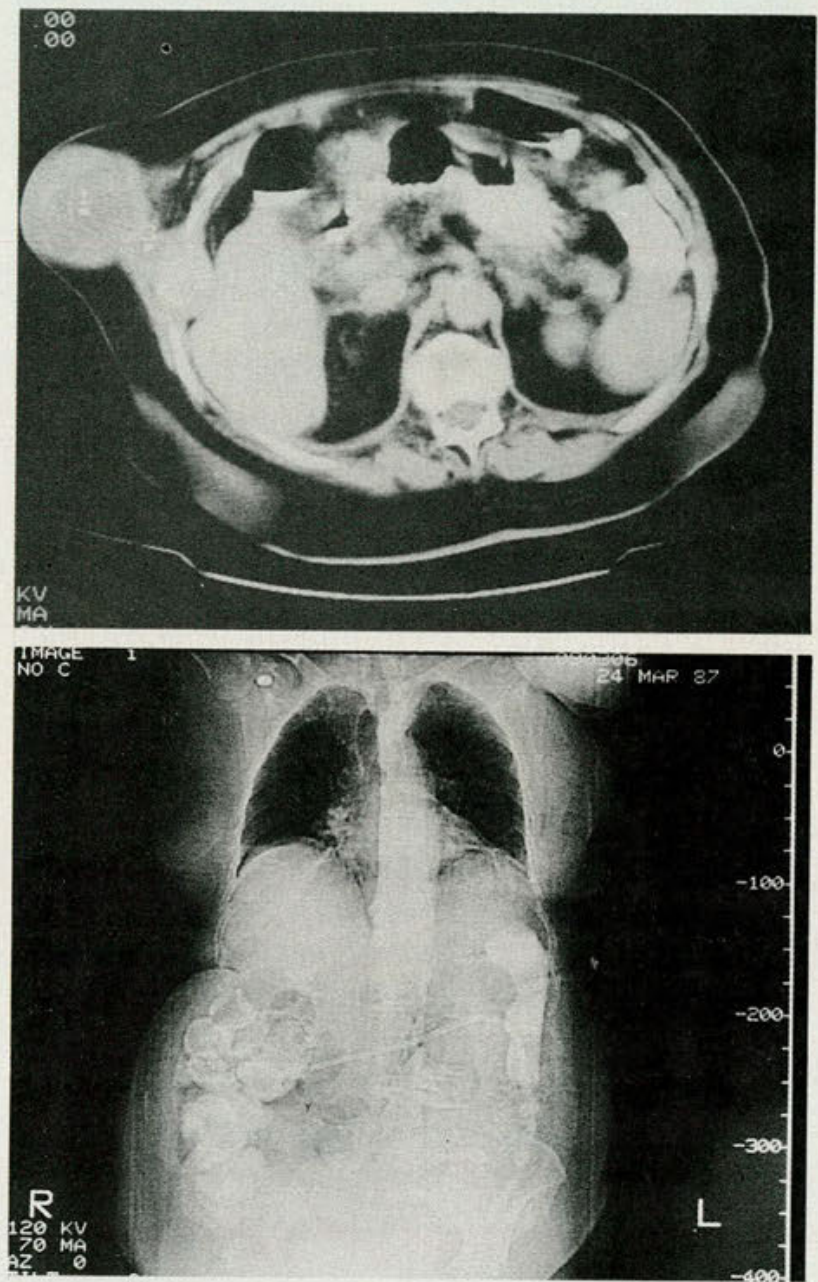

Figure 7. Top: Axial section of CT scan demonstrates low-density mass of soft tissue arising from and extending into the site of previous internal stent insertion almost 3.5 years later. Bottom: Scout view shows a mass between the right breast and gluteal muscle (arrow). $\mathrm{Pa}$ thologic evaluation of the excised mass revealed metastatic mucin-secreting adenocarcinoma. 

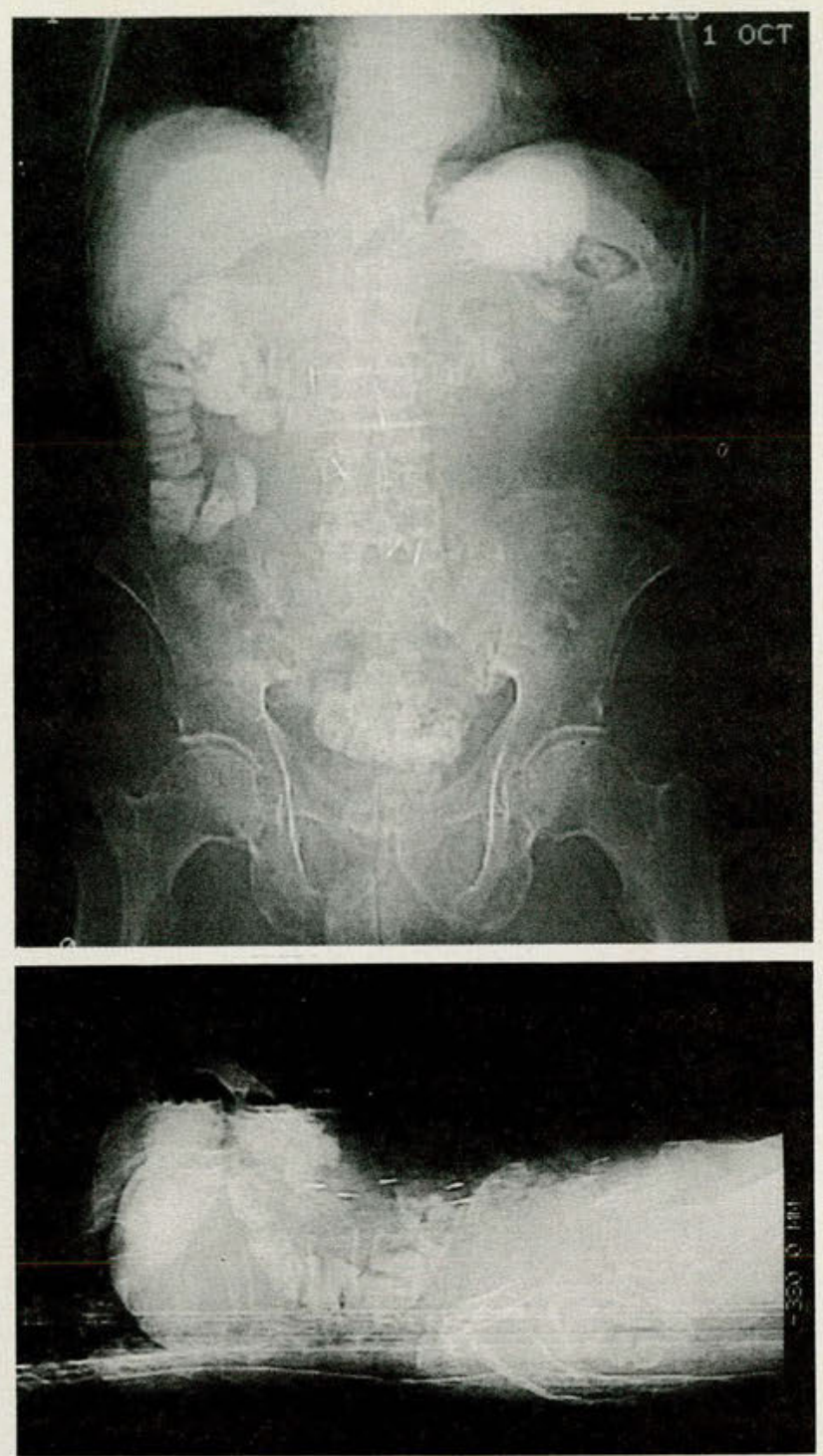

Figure 8. Scout views of CT demonstrate the relatively short craniocaudal dimensions of the liver. Also note emphysematous lung fields bilaterally, with deep costophrenic angles.

phrenic region, with the development of a hydropneumothorax on the right side.

Stent insertion proceeded, and a chest thoracotomy drainage tube was inserted immediately thereafter. The external temporary catheter was placed for external drainage. The thoracostomy tube drained bile-stained fluid for the next 7 days (approximately 200 to $250 \mathrm{~mL} /$ day). The external catheter was removed, and hepatobiliary scanning was performed to evalu- ate for a possible biliary-pleural fistula. The scan showed no fistulous communication, and the patient underwent tetracycline instillation into the right pleural space for the persistent pneumothorax. The fixating suture was left intact to hold the stent in position; the suture also would remain across the pleura. A repeated chest film 1 week later showed resolution of the pneumothorax with minimal residual pleural effusion on the right. The patient was subsequently discharged and he died 1 week later. An autopsy was not done.

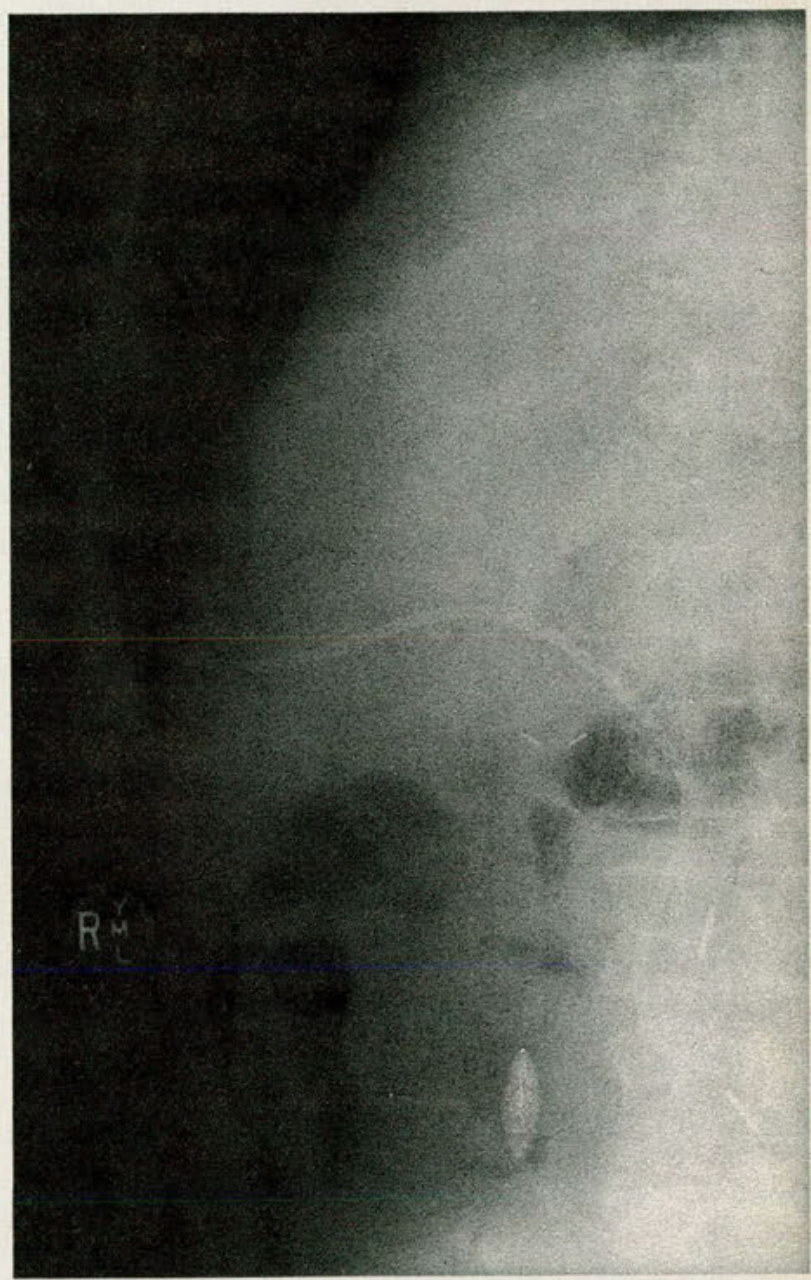

Figure 9. Left lateral film of patient in decubitus position, which was taken after the endoprosthetic insertion procedure, shows previously unrecognized transpleural passage of the Ring external/internal drainage catheter. Clips in the right upper quadrant are from previous cholecystectomy; those in the lower quadrant and in the midline are from an earlier resection for adenocarcinoma. 



\section{Now the first name in baby food is the new name in formula.}

New Gerber ${ }_{\mathrm{r}}$ Baby Formula has a nutrient balance that has been successfully fed to millions of babies.

The $82: 18$ casein/whey protein composition is one that is exceptionally well tolerated by babies. In a recent clinical study, babies fed the Gerber ${ }^{\mathrm{TM}}$ Baby Formula formulation not only tolerated it wellconsistent with historical controls - but had similar measurements of growth and development to those fed breast milk and milk-based formulas.'

Breast milk is the best for babies... but no formula is more nutritious than Gerber ${ }_{т м}$ Baby Formula.

Gerber $^{\mathrm{TM}}$ Baby Formula closely resembles average breast milk in micronutrient composition. It also is formulated to provide the levels of nutrients specified by the Infant Formula Act.

\section{Gerber ${ }_{\mathrm{x}}$ Baby Formula Nutrient Sources}

Protein - Nonfat milk 82:18 casein/whey

Fat - All vegetable oil

CHO - Lactose

\section{Reference}

1. An evaluation of casein-based infant formula in newborns from birth until four months of age. Data on file.

\section{Three generations of babies have} thrived on Gerber products.

For over 60 years, the Gerber name has been one that mothers and doctors trust. And we want to assure you that, because mothers trust Gerber, we have included in all our advertising our belief and yours that mother's milk is the ideal first food for babies. After three generations, the name Gerber has become synonymous with quality, consistency, and care.

Gerber $^{\mathrm{TM}}$ Baby Formula is available as low-iron and iron-fortified infant formula. Each comes in three forms: ready-to-use liquid, concentrated liquid, and powder.
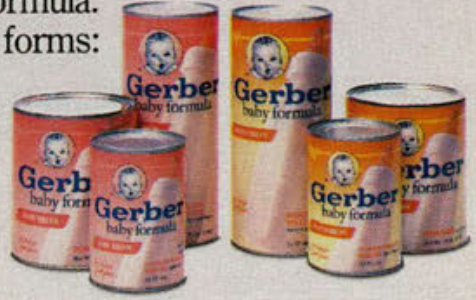

For more information call 1-800-828-9119.

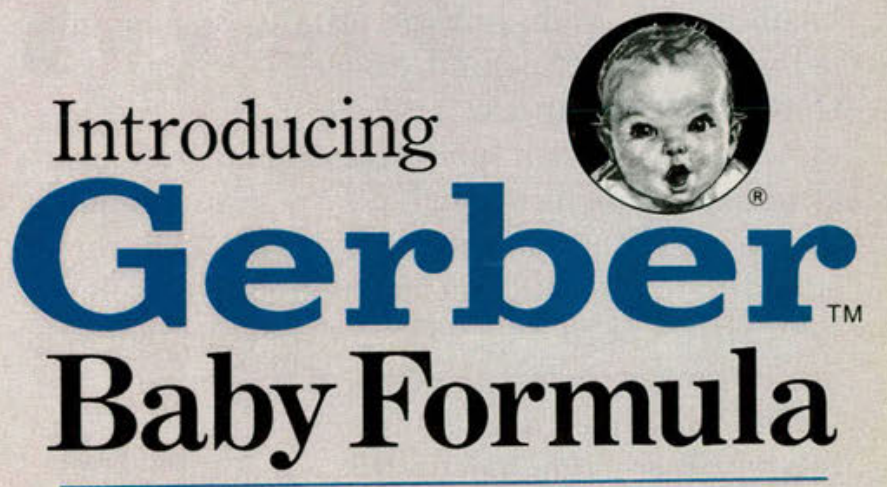

Because "Babies are our business.... 


\begin{tabular}{|c|c|}
\hline \multicolumn{2}{|c|}{$\begin{array}{c}\text { Table } 2 \\
\text { Dilation of Extrahepatic and Intrahepatic } \\
\text { Biliary Ducts }\end{array}$} \\
\hline Common & Uncommon \\
\hline $\begin{array}{l}\text { Carcinoma of pancreas, } \\
\text { common duct, or } \\
\text { ampulla } \\
\text { Gallstone, ductal } \\
\text { Chronic pancreatitis } \\
\text { Stricture (postsurgical, } \\
\text { traumatic, or } \\
\text { inflammatory) }\end{array}$ & $\begin{array}{l}\text { Congenital } \\
\text { Biliary atresia } \\
\text { Caroli's disease } \\
\text { Choledochal cyst } \\
\text { Diaphragm of hepatic duct } \\
\text { Duodenal diverticulum } \\
\text { (compression) } \\
\text { Hepatic fibrosis with } \\
\text { ductal ectasia } \\
\text { Stricture } \\
\text { Inflammatory } \\
\text { Duodenal ulcer } \\
\text { (penetrating) } \\
\text { Liver abscess (including) } \\
\text { hydatid cyst) } \\
\text { Mirizzi syndrome } \\
\text { Papillitis or fibrosis of } \\
\text { sphincter of Oddi } \\
\text { Parasites (clonorchiasis, } \\
\text { fascioliasis, ascariasis) } \\
\text { Sarcoidosis } \\
\text { Sclerosing cholangitis, } \\
\text { primary or secondary } \\
\text { - Neoplasm (metastatic or } \\
\text { other primary) } \\
\text { Retroperitoneal fibrosis } \\
\text { Aneurysm of hepatic } \\
\text { artery or aorta }\end{array}$ \\
\hline $\begin{array}{l}\text { Adapted by permission from Al } \\
\text { biliary ducts (extrahepatic, } \\
1981 ; 16(1): 3 \text {. }\end{array}$ & $\begin{array}{l}\text { der ES, Mitchell SE: Dilatation of } \\
\text { ahepatic). Semin Roentgenol }\end{array}$ \\
\hline
\end{tabular}

\section{Discussion}

The workup and treatment of the jaundiced patient can represent quite a challenge to the primary physician. The patient's history and the systemic workup may help to narrow the possibilities, but it is not until the results of basic ancillary diagnostic studies (biochemical analysis, ultrasound, and CT) are obtained that the clinician can make a differential diagnosis. Even with laboratory and ultrasound studies indicating an obstructive phenomenon, the cause is not clear-cut (see Table 2) ${ }^{16}$ Further diagnostic studies (biochemical, microbiological, CT, ERCP, PTC, and needle biopsy) are often necessary to confirm the cause.

The diagnosis and treatment of malignant biliary obstruction has undergone many refine-

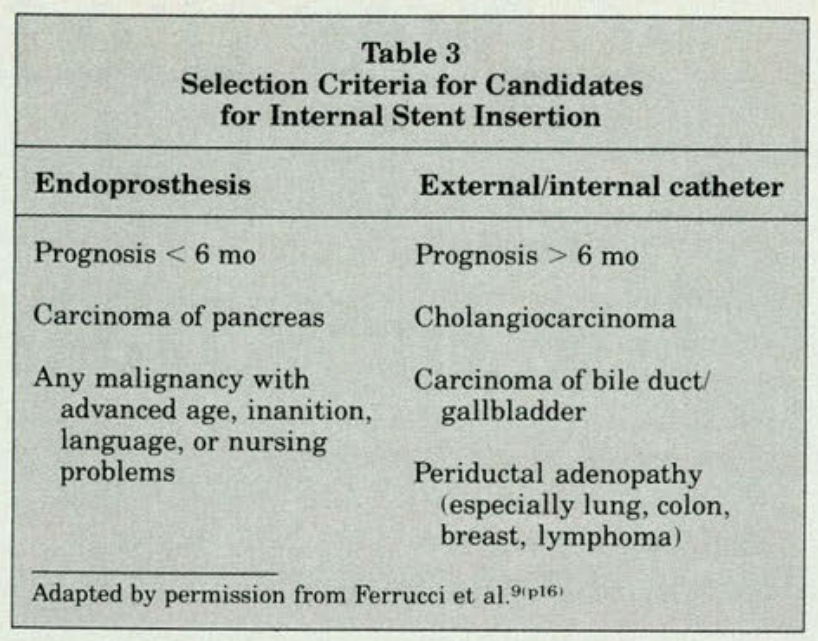

ments. Even reviewing our own data, we are now able to define better which candidates should undergo internal stenting rather than external/internal drainage catheter therapy. Other groups have proposed patient selection criteria (Table 3) ${ }^{9}$ We believe that the location and cause of the obstruction play a major role in patient selection for internal stenting. However, additional emphasis needs to be placed on the patient's underlying physical condition and the prognosis, so that the selected therapy can provide the greatest benefit to the patient. Patients with highly advanced primary malignancies would probably fare better with external/internal catheter therapy due to their expected short lifespan, and usually poor underlying condition.

Also, patients with metastasis high in the porta hepatis should undergo external/internal therapy because of the relatively short intrahepatic duct available proximal to the obstruction. Although none of our patients died as a direct result of the procedure, even a minor complication occurring in a markedly compromised individual may significantly affect his or her remaining life expectancy, and may even lead to death prematurely. Patients with debris-laden bile commonly have decreased catheter patency; therefore, these patients should undergo prolonged external/internal drainage to assess if the bile will clear. This procedure simplifies subsequent catheter care and prevents the need to remove the en- 
doprosthesis and start anew to replace a catheter.

We recommend that stent removal for obstruction be done endoscopically by a gastroenterologist. We believe it is the least traumatic approach, and allows the percutaneous procedure to be performed on a relatively nontraumatized system (ie, no blood clots are present).

Another concern that has prompted enhanced scrutiny of patients referred for internal stenting is the high-dose radiation to which the patient and the operators are exposed. As reported by Mendez and associates, ${ }^{17}$ procedure times of 2 to 4 hours are not uncommon, even when performed by the more experienced members of the group. Our experience has been similar, especially with the more complicated cases of multiple intrahepatic ductal lesions or of those resistant to dilation and stent insertion. In comparison, more straightforward cases average 1 to 2 hours.

Despite two serious complications (hydropneumothorax and subcapsular/subcutaneous abscess), none of our patients died as a direct result of stent insertion. Also, none required transfusion or surgery for bleeding complications. Except for the placement of a catheter across the pleura, no other thoracic or abdominal viscera were violated.

\section{Summary}

Internal biliary stent insertion has established a definite place in the interventional radiologists' armamentarium of nonsurgical treatment of malignant obstructive jaundice. However, as with all invasive techniques, the patient's comfort; the high radiation doses to the patient and to the radiologist and the technical staff; and the potential complications must be weighed against the anticipated gains from that intervention. The challenge remains to select the patients who would benefit the most from these two forms (endoprosthesis and external/internal catheter) of nonsurgical palliative therapy.

1. Molnar W, Stockum AE: Relief of obstructive jaundice through percutaneous transhepatic catheter: A new therapeutic method. AJR 1974;122:356-367.

2. Ring EJ, Oleaga JA, Freiman DB, et al: Therapeutic applications of catheter cholangiography. Radiology 1978;128:333338.

3. Pereiras RV, Rheingold OJ, Hutson D, et al: Relief of malignant obstructive jaundice by percutaneous insertion of a permanent prosthesis in the biliary tree. Ann Intern Med 1978;89:589-593.

4. Ferrucci JT Jr, Mueller PR, Harbin WP: Percutaneous transhepatic biliary drainage. Radiology 1980;135:1-13.

5. Mueller PR, vanSonnenberg E, Ferrucci JT Jr: Percutaneous biliary drainage: Technical and catheter-related problems in 200 procedures. AJR 1982;138:17-23.

6. Honickman SP, Mueller PR, Ferrucci JT Jr, et al: Malpositioned biliary endoprosthesis: Retrieval using a vascular balloon catheter. Radiology 1982;144:423-425.

7. Miskowiak J, Mygind T, Baden H, et al: Biliary endoprosthesis secured by a subcutaneous button to prevent dislocation. AJR 1982;139:1019-1020.

8. Mueller PR, Ferrucci JT Jr, vanSonnenberg E, et al: Obstruction of the left hepatic duct: Diagnosis and treatment by selective fine-needle cholangiography and percutaneous biliary drainage. Radiology 1982;145:297-302.

9. Ferrucci JT Jr, Adson MA, Mueller PR, et al: Advances in the radiology of jaundice: A symposium and review. AJR 1983;141:1-20.

10. Coons HG, Carey PH: Large-bore, long biliary endoprostheses (biliary stents) for improved drainage. Radiology 1983;148:89-94.

11. Teplick SK, Haskin PH, Goldstein RC, et al: A new biliary endoprosthesis. AJR 1983;141:799-801.

12. Silverberg E, Lubera J: Cancer statistics, 1987. CA 1987;37:219.

13. Devita VT, Hellman S, Rosenberg SA: Cancer Principles and Practice of Oncology, ed 2. Philadelphia, JB Lippincott Co, 1985, pp 858-862.

14. Schein CJ, Stern WZ, Jacobson HG: The hepatic ductal system: A correlation of endoscopic and roentgenographic findings. Surgery 1962;51:718-723.

15. Netter FH: Digestive System: The Lower Digestive Tract: Ciba Collection of Medical Illustrations. Summit, NJ, CibaGeigy Corp, 1962, vol 3, part 2, p 4.

16. Alexander ES, Mitchell SE: Dilatation of biliary ducts (intrahepatic and extrahepatic). Semin Roentgenol 1981;16(1):3. 17. Mendez G, Russell E, Lepage JR, et al: Abandonment of endoprosthetic drainage technique in malignant biliary obstruction. AJR 1984;143:617-622. 

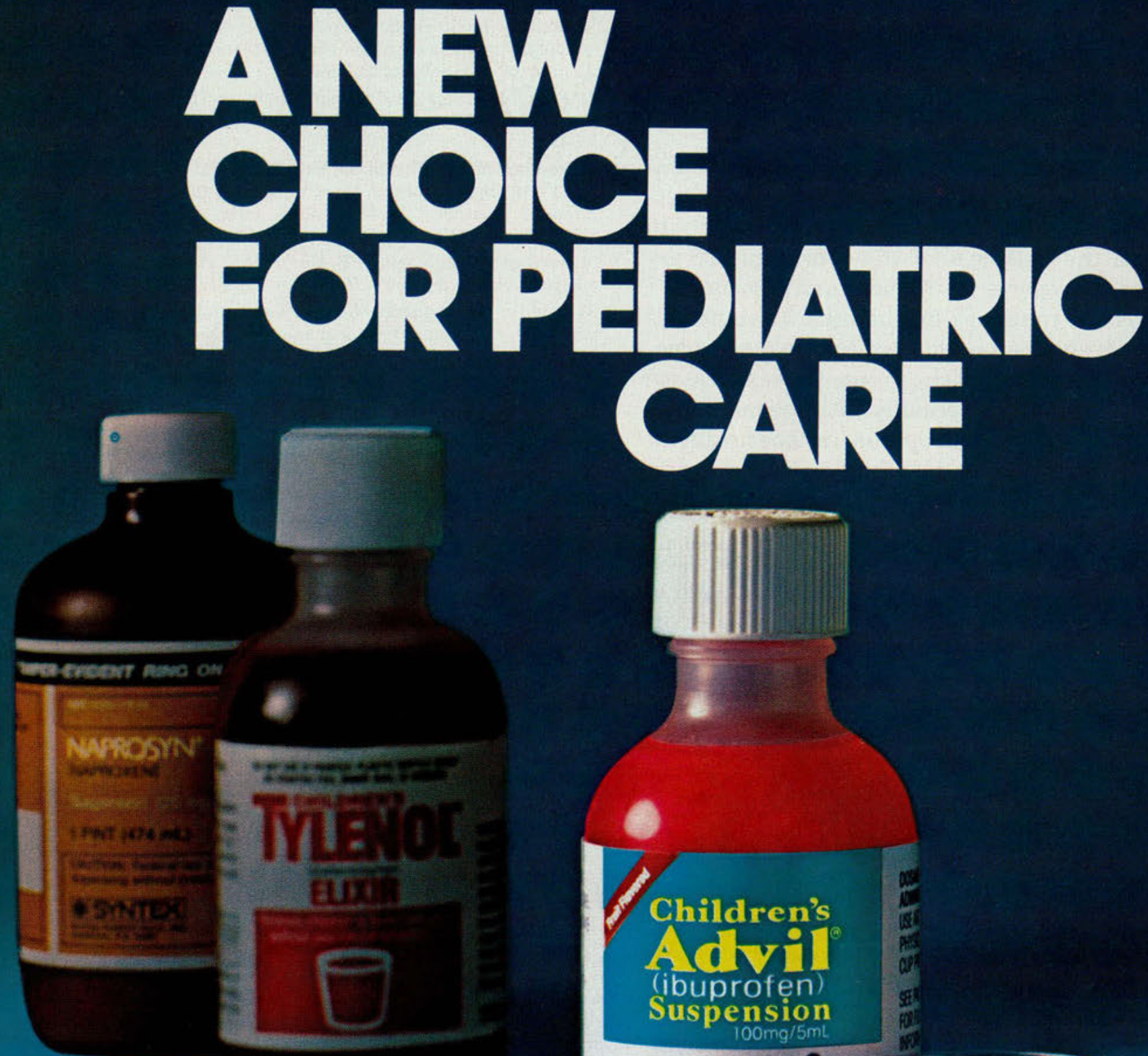


\section{EFFECTIVELY REDUCES FEVER}

Clinical trials have documented the significant antipyretic efficacy of Children's Advil ${ }^{\circledR}$ (ibuprofen) Suspension. ${ }^{1,2}$

\section{EFFECTIVELY REDUCES INFLAMMATION IN JUVENILE ARTHRITIS}

Children's Advil ${ }^{\circledR}$ (ibuprofen) Suspension produced significant improvement in all efficacy parameters - including number of swollen and painful joints, grip strength, and duration of morning stiffness. ${ }^{3}$

\section{WELL TOLERATED}

at clinically effective doses ranging from 20 to $50 \mathrm{mg} / \mathrm{kg} / \mathrm{day}$

\section{BY PRESCRIPTION ONLY}

Please see following page for a brief summary of prescribing information.
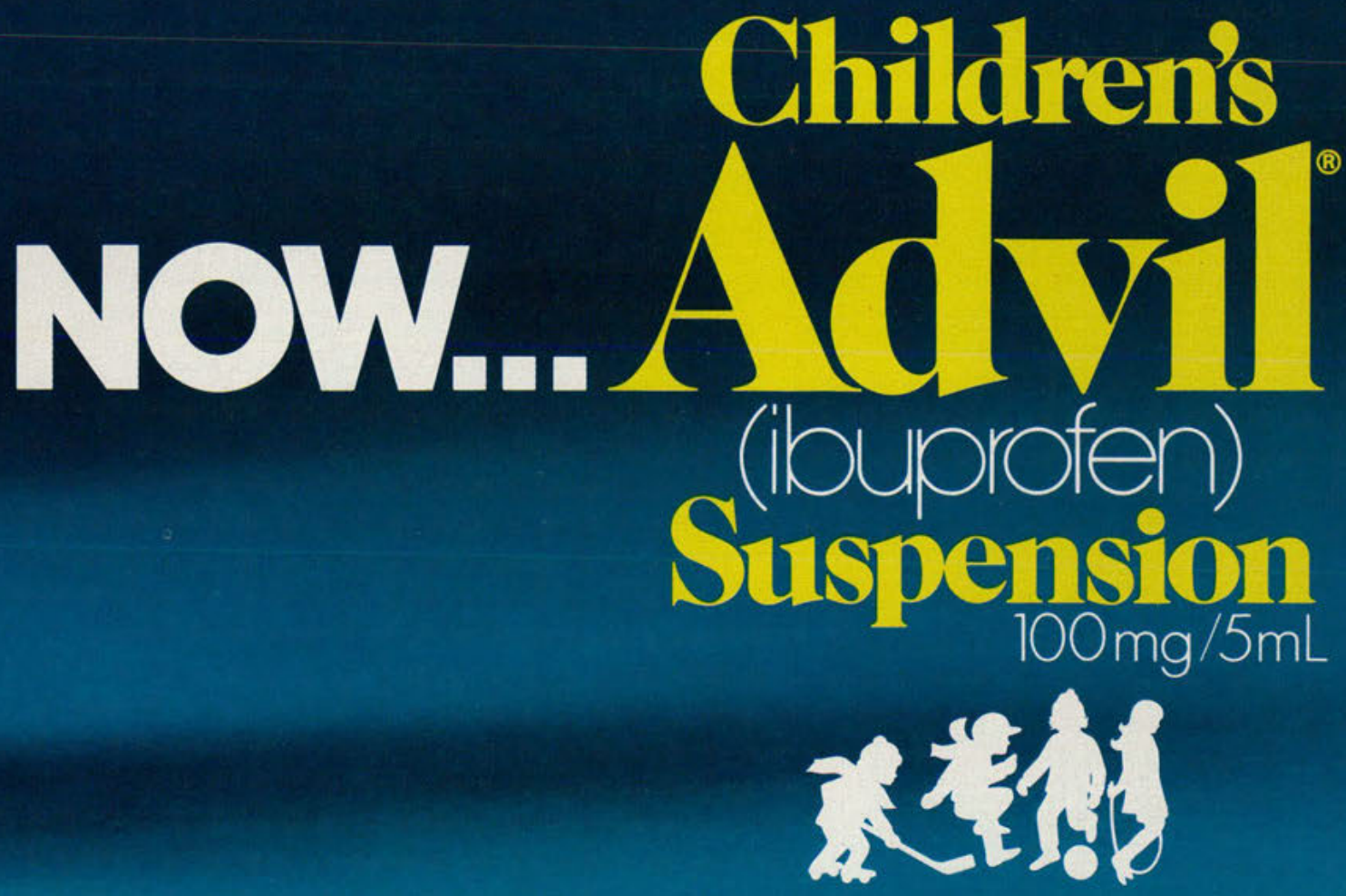


\section{Children's \\ A NEW CHOICE
FOR PEDIATRIC CARE}
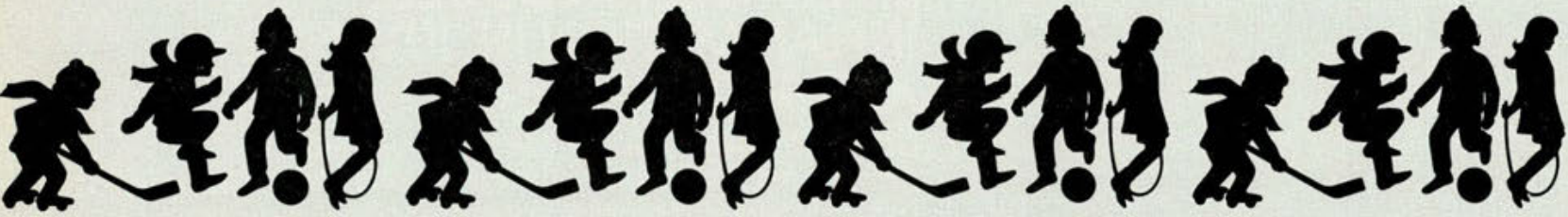

BRIEF SUMMARY OF PRESCRIBING INFORMATION

CONIRANDICATIONS: Patients hypersensitive to ibuprofen or patients with all or part of the syn.

drome of nasal polyps, angioedema, and bronchospastic reactivity to aspirin or other nonsteroid

WARNINGS: Risk of G Ulcerations, Bleeding, and Pertoration with NSAID Therapy: Physician

should remain alert for ulceration and bleeding in patients treated chronically with NSAIDS even

the absence of previous Gl tract symptoms. In patients observed in clinical trials of several month's

to two years' duration, symptomatic upper Gl ulcers, gross bleeding or perforation appear to occ

in approximately $1 \%$ of patients treated for $3-6$ months, and in about $2-4 \%$ of patients treated for

Except for a prior history of serious Gl events and other risk factors known to be associated with pep fic ulcer disease, no risk factors have been associated with increased risk Elderly or debilitated patients seem to tolerate ulceration or bleeding less well than other individuals and most sponta

neous reports of fatal Glevents are in this population

iceration and bleeding can occur without warning symptoms, physicians sh

Blurred and/or diminished vision scotomato, and/or changes in color vision have been reported a patient develops such complaints the drug should be discontinued and the patient should have an ophthalmologic examination.

Fluid retention and edema have been reported with ibuprofen, therefore, the drug should be used with caution in patients with a history of cardiac decompensation or hypertension.

buprofen can inhibit platelet aggregation and prolong bleeding time. CHILDRENSADVI:

SUSPENSION should be used with caution in persons with intrinsic coagulation defects and those on anticoagulant therapy.

The antipyrefic and anti-inflammatory octivity of ibuprofen may reduce fever and inflammation. thus diminishing their utility as diagnostic signs in detecting complications of presumed noninfec( noninflammatory painful conditions

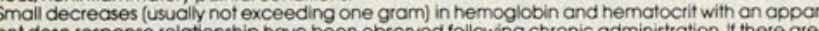
observed following chronic administration. If there ate no signs of bleeding, it is probably not clinically important.

no signs of bleeding it is probably nof cilrical insufficiency. patients on prolonged corticosteroid therapy should have their therapy tapered slowly when CHIDRENS ADVL * SUSPENSION is added to the treatment program

Aseptic meningitis: Aseptic meningitis with fever and coma has been observed on rare occasions in odult patients on ibuprofen therapy. Although it is more likely to occur in patients with systemic lupus erythematosus and related connective tissue diseases, it has been reported in adult patients

who do not have underlying chronic disease. If signs or symptoms of meningitis develop in a
patient on CHILRENS ADVIL * SUSPENSION, the possibility of its being related to ibuprofen should be

Renal Effects: As with other nonsteroidal anti-inflammatory drugs, long-term administration of

ibuprofen to animals has resulted in renal papillary necrosis and other abnormal renal patholog in humans there have been reports of acute interstifial nephritis with hematuria. proteinuria. and occasionally nephrotic syndrome.

A second form of renal toxicity has been seen in patients with prerenal conditions leading to reducfion in renal blood flow or blood volume. In these patients, administration of a nonsteroidal anti: inflammatory drug may cause a dose dependent reduction in prostaglandin formation and precipitate overt renal decompensation. Patients at greatest risk of this reaction are those with impaired renal function heart failure, liver dysfunction, and those taking diuretics and the elderly Those patients at high risk who chronically take CHILDRENS ADVIL * SUSPENSION should have rene function monitored if they have signs or symptoms of azotemia. Discontinuation of nonsteraida anti-inflammatory drug therapy is typically tollowed by recovery to the pretreatment state. Sinclion should be closely monitored and areduction in dosage shoul be anticipcted to croid function should be closely monitored and a reduction in dosage should be anticipated to avoid

likely benefits of treatment with CHIIDRENS ADVIL = SUSPENSIO

Laboratory Tests: Meaningful ( 3 times the upper limit of normal) elevations of SGPT or SGOT (AST) occurred in controlled clinical trials in less than $1 \%$ of patients. A patient with symptoms and/or signs suggesting liver dysfunction, or in whom an abnormal liver test has occurred, should be evaluated for evidence of the development of more severe hepatic reactions while on therapy with ibuprofen. If abnormal liver tests persist or worsen if clinical signs and symptoms consistent with liver disease develop, or if systemic manifestations occur, CHILDREN'S ADVIL * SUSPENSION should be

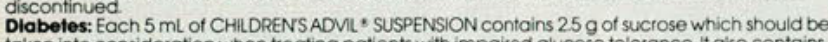
taken into consideration when treating patients with impaired glucose tolerance. It also contains ciated with cian may wish to review the patients dietary intake of sorbitol from other sources

Drug Interactions: Coumarin type Anticoagulants: Bleeding has been reported when ibuproten and other nonsteroidal anti-inflammatory agents have been administered to patients on coumarin-type anticoagulants; the physician should be cautious when administering CHILDRENS ADVIL SUSPENSION io patients on anticoagulants

Methotrexate: in vitro studies indicate that ibuprofen could enhance the toxicity of methotrexate Caution should be used if CHILDRENS ADVI * SUSPENSION is administered concomitantly witt

$\mathrm{H}_{2}$ Antogononists: in studies with human volunteers, coadministration of cimetidine or ranitidine with buprofen had no substantive effect on ibuprofen serum concentrations

Furosemide: : buprofen can reduce the nafiuretic eftect of furosemide and thiczides in some

observed closely for signs of renal failure as well as to assure diuretic efficacy.

Uthium: lbuprofen produced an elevation of plasma lithium levels (15\%) and a reduction in rena (a) gaministration. Patients shou

Pregnancy: Administration of ibuprofen is not recommended during pregnancy or for use by

nursing mothers.

Intants: Safety and efficacy of CHIDRENS ADVL * SUSPENSION in children below the oge of

12 months have not been established. ADVL * SUSPENSION is gastrointestinal. In clinical trials among adults involving chronic administration of ibuprofen, the percentage of patients reporting one or more gastrointestinal complaints ranged

Incidence Greater Than $1 \%$ (but less than $3 \%$ ), Probable Causal Relationship

Incidence Greater Than $1 \%$ (but less than $3 \%$ ), Probable Causal Relationship
Gastrointestinal: Nausea." epigastric pain " heartburn" diarrhea, abdominal distress, nausea and vomiting indigestion, constipation, abdominal cramps or pain, fullness of the GI tract (bloating and fiatulence)

Central Nervous System: Dizziness: headache, nervousness.

Dermotologic: Rash (including moculopopular type): pruritus

Special Senses Tinnitus
Metabolic/Endocrine: Decreased appetite

Cardiovascular, Edema, fluid retention (generally responds promptly to drug discontinuation) SEe PRECAUTIONS.

Reactions occurring in $3 \%$ to $9 \%$ of adult patients treated with ibuprofer

Precise Incidence Unknown (but less than 1\%), Probable Causal Relationship Gastroinfestinal: Gastric or duodenal ulcer with bleeding and/or perforation, gastrointestinal hemorthage, panciection tests.

drome, alopecia

Central Nervous System: Depression, insomnia, confusion emotional lability, somnolence, aseptic meningitis with fever and coma.

Special Senses Hearing loss, amblyopia (blurred and/or diminished vision, scotomata and/or changes in color vision) (see PRECAUTIONS)

Hematologic: Neutropenia. agranulocytosis, aplastic anemia hemolytic anemia (sometimes Coombs' posifive), thrombocytopenia with or without purpura, eosinophilia, decreases in hemoglobin and hematocrit (see PRECAUTIONS).

Cardiovascular. Congestive heart faliure in patients with marginal cardiac function elevated

blood pressure, palpilictions

Allergic: Syndrome of abdominal pain, fever, chills, nausea and vomiting anaphylaxis, bron chospasm (see CONIIRAINDICATIONS).

tients with preexisting significantly impaired renal function (see PRECAUIIONS), decreased creatinine clearance, polyuria, azotemia, cystitis, hematuric

Mrecise Incidence Unknown (but less than 1\%), Causal Relationship Unknown

Central Nervous System: Paresthesias, hallucinations, dream abnormalities, pseudotumor cerebri. Dermatologic. Ioxic epidermal necrolysis, photocilergic skin reoctions.

Special Senses Conjunctivitis diplopia, optic neurtis cataracts.

Hematologic: Bleeding episodes (eg. epistaxis, menornagia).

Metabolic/Endocrine Gynecomastia, hypoglycemic reactions, acidos is

Cardiovascular: Arthythmias (sinus tochycardia, sinus bradycardia)

thiein vasculitis, angioedema

OVERDOSAGE: Patients with a history of ingestion of greater than $100 \mathrm{mg} / \mathrm{kg}$ should have induced Supportive ther my include dose orai administration of activated charcoal may be useful drug is acidic and excreted in the urine, administration of sodium bicarbonate and induction of diuresis may be beneficio

DOSAGE AND ADMINISTRATION: Juvenile arthritis: $30-40 \mathrm{mg} / \mathrm{kg}$ doy in 3 or 4 divided doses Fever $5 \mathrm{mg} / \mathrm{kg}$ if baseline temperature is $102.5 \%$ or below or $10 \mathrm{mg} / \mathrm{kg}$ if baseline temperature is grecter than $1025^{\circ}$ Fevery 6-8 hours (children), $400 \mathrm{mg}$ every $4-6$ hours (adults) A A and OA: $1200-3200 \mathrm{mg}$ per day in 3 or 4 divided doses Mild to moderate pain in adults $400 \mathrm{mg}$ every 4 to 6 hours Dysmenorrined: $400 \mathrm{mg}$ every 4 hours

HOW SUPPLIED: 4 and 16 oz bottles

\section{References:}

1. Walson PD, Galletta G. Braden NJ. Alexander L. Ibuprofen acetaminophen and placebo treat 2. Independent Clinical Study. Reduction of Fever in Children Multiple Dose. Data on file, Medical Department, Whitehall Laboratories:

3. Independent Clinical Study. Juvenile Arthritis, Data on file, Medical Department, Whitehall Laboratories

WHITEHALL LABORATORIES

A HEALTH CARE DIMION OF

AMERICAN HOME PRODUCTS CORPORATION

(c) 1989 Whitehall Laboratories, N.Y, N.Y 
The \#1 prescribed allergy P in the U.S. and worldwia

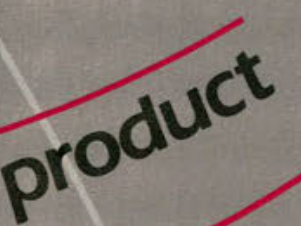

\section{RAPID,} UNSURPASSED RELIEF

Relief starts fast - most hay fever patients experience significant relief within 1 hour $^{1+}$

Relief peaks fast - within 3-4 hours ${ }^{2 * *}$

Relief is unsurpassed - proven in 30 double-blind clinical studies ${ }^{3-7}$

Relief is convenient - for high patient compliance ${ }^{\dagger \dagger}$

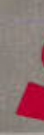
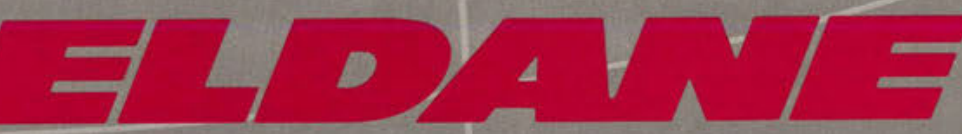

(terfenadine) 60 mg tablets BID

for seasonal allergic rhinitis

\section{The ideal profile for fast, on-the-job relief}

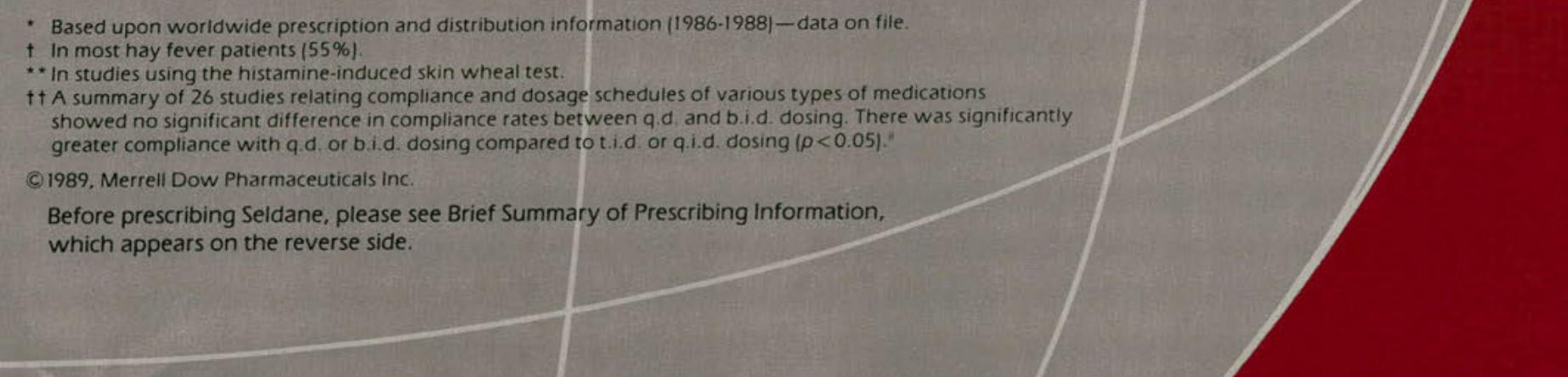



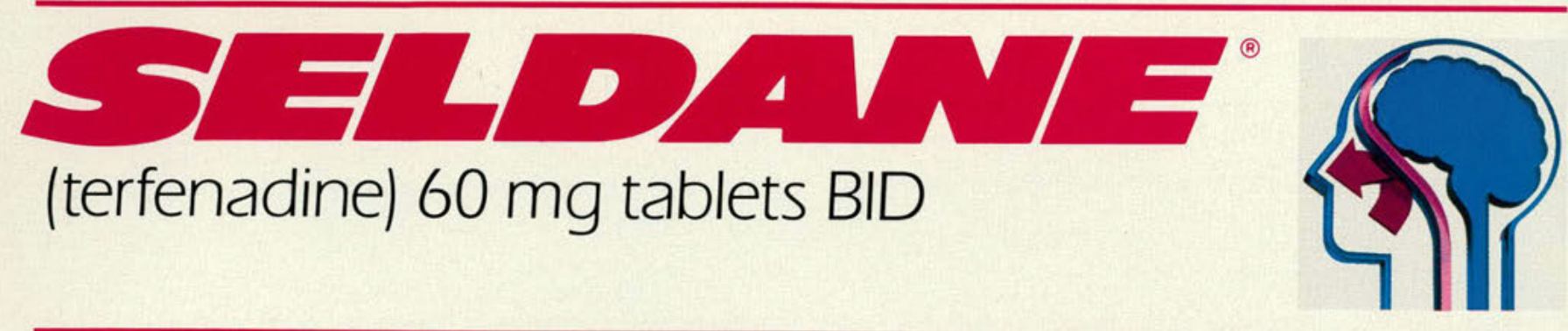

\section{- Fast, unsurpassed relief \\ Efficacy maintained in through-the-season use $\mathrm{e}^{9-11}$ - Lets patients stay alert so they can perform at their best \\ - B.i.d. dosing for high patient compliance}

Seldane ${ }^{\circledR}$ (terfenadine) $60 \mathrm{mg}$ Tablets

CAUTION: Federal law prohibits dispensing without prescription.

\section{DESCRIPTION}

Seldane (terfenadine) is available as tablets for oral administration. Each tablet contains $60 \mathrm{mg}$ terfenadine. Tablets also contain, as inactive ingredients: corn starch, gelatin, lactose, magnesium stear ate, and sodium bicarbonate.

INDICATIONS AND USAGE

Seldane is indicated for the relief of symptoms associated with seasonal allergic minitis such as sneezing, rhinorrhea, pruritus, and lacrimation.

CONTRAINDICATIONS

CONTRAINDICATIONS
Seldane is contraindicated in patients with a known hypersensitivity to terfenadine or any of its ingredients.

\section{PRECAUTIONS}

Information for patients

Patients taking Seldane should receive the following information and instructions. Antihistamines are prescribed to reduce allergic symptoms. Patients should be questioned about pregnancy or lactation before starting Seldane therapy, since the drug should be used in pregnancy or lactation only if the potential benefit justifies the potential risk to fetus or baby. Patients should be instructed to take Seldane only as needed and not to exceed the prescribed dose. Patients should also be instructed to store this medication in a tightly closed container in a cool, dry place, away from heat or direct sunlight, and away from children

Carcinogenesis, mutagenesis, impairment of fertility

Oral doses of terfenadine, corresponding to 63 times the recommended human daily dose, in mice for 18 months or in rats for 24 months, revealed no evidence of tumorigenicity. Microbial and micronucleus test assays with terfenadine have revealed no evidence of mutagenesis.

Reproduction and fertility studies in rats showed no effects on male or female fertility at oral doses of up to 21 times the human daily dose. At 63 times the human daily dose there was a small but significan reduction in implants and at 125 times the human daily dose reduced implants and increased post-implantation losses were observed, which were judged to be secondary to maternal toxicity.

Pregnancy Category C

There was no evidence of animal teratogenicity. Reproduction studies have been performed in rats at doses 63 times and 125 times the human daily dose and have revealed decreased pup weight gain and survival when terfenadine was administered throughout pregnancy and lactation. There are no adequate and well-controlled studies in pregnant women. Seldane should be used during pregnancy only if the potential benefit justifies the potential risk to the fetus.

Nonteratogenic effects

Seldane is not recommended for nursing women. The drug has caused decreased pup weight gain and survival in rats given doses 63 times and 125 times the human daily dose throughout pregnancy and lactation. Effects on pups exposed to Seldane only during lactation are not known, and there are no adequate and well-controlled studies in women during lactation.

Pediatric use

Safety and effectiveness of Seldane in children below the age of 12 years have not been established. General

Consideration should be given to potential anticholinergic (drying) effects in patients with lower airway disease, including asthma.

ADVERSE REACTIONS

Experience from clinical studies, including both controlled and uncontrolled studies involving more than 2,400 patients who received Seldane, provides information on adverse experience incidence for periods of a few days up to six months. The usual dose in these studies was $60 \mathrm{mg}$ twice daily, but in a smal number of patients, the dose was as low as $20 \mathrm{mg}$ twice a day, or as high as $600 \mathrm{mg}$ daily.

In controlled clinical studies using the recommended dose of $60 \mathrm{mg}$ b.i.d., the incidence of reported adverse effects in patients receiving Seldane was similar to that reported in patients receiving placebo. (See Table below.)

ADVERSE EVENTS REPORTED IN CLINICAL TRIALS

\begin{tabular}{|c|c|c|c|c|c|}
\hline \multirow[b]{2}{*}{$\begin{array}{c}\text { Adverse } \\
\text { Event }\end{array}$} & \multicolumn{5}{|c|}{ Percent of Patients Reporting } \\
\hline & $\begin{array}{l}\text { Co } \\
\text { Seldane } \\
W=781\end{array}$ & $\begin{array}{l}\text { trolled Stu } \\
\text { Placebo } \\
N=665\end{array}$ & $\begin{array}{l}\text { udies } \\
\text { Control. } \\
M=626 *\end{array}$ & \begin{tabular}{|l} 
All Clinical \\
Seldane \\
$\mathbf{N}=\mathbf{2 4 6 2}$
\end{tabular} & $\begin{array}{l}\text { Studies** } \\
\text { Placebo } \\
N=1478\end{array}$ \\
\hline \multicolumn{6}{|l|}{ Central Nervous System } \\
\hline $\begin{array}{l}\text { Drowsiness } \\
\text { Headache } \\
\text { Fatigue } \\
\text { Diziness } \\
\text { Nervousness } \\
\text { Weakness } \\
\text { Appetite Increase }\end{array}$ & $\begin{array}{l}9.0 \\
6.3 \\
2.9 \\
1.4 \\
0.9 \\
0.9 \\
0.6\end{array}$ & $\begin{array}{l}8.1 \\
7.4 \\
0.9 \\
1.1 \\
0.2 \\
0.6 \\
0.0\end{array}$ & $\begin{array}{r}18.1 \\
3.8 \\
5.8 \\
1.0 \\
0.6 \\
0.2 \\
0.0\end{array}$ & $\begin{array}{r}8.5 \\
15.8 \\
4.5 \\
1.5 \\
1.7 \\
0.6 \\
0.5\end{array}$ & $\begin{array}{r}8.2 \\
11.2 \\
3.0 \\
1.2 \\
1.0 \\
0.5 \\
0.0\end{array}$ \\
\hline \multicolumn{6}{|l|}{$\begin{array}{l}\text { Gastrointestinal System } \\
\text { Gastrointestinal Distress } \\
\text { (Abdominal distress, } \\
\text { Nausea, Vomiting. }\end{array}$} \\
\hline $\begin{array}{l}\text { Nausea, Vomiting, } \\
\text { Change in Bowel habits) } \\
\text { Eye, Ear, Nose, and Throat }\end{array}$ & 4.6 & 3.0 & 2.7 & 7.6 & 5.4 \\
\hline $\begin{array}{l}\text { Dry Mouth/ Nose/Throat } \\
\text { Cough } \\
\text { Sore Throat } \\
\text { Epistaxis }\end{array}$ & $\begin{array}{l}2.3 \\
0.9 \\
0.5 \\
0.0\end{array}$ & $\begin{array}{l}1.8 \\
0.2 \\
0.3 \\
0.8\end{array}$ & $\begin{array}{l}3.5 \\
0.5 \\
0.5 \\
0.2\end{array}$ & $\begin{array}{l}4.8 \\
2.5 \\
3.2 \\
0.7\end{array}$ & $\begin{array}{l}3.1 \\
1.7 \\
1.6 \\
0.4\end{array}$ \\
\hline \multicolumn{6}{|l|}{$\begin{array}{l}\text { Skin } \\
\text { Eruption (including rash }\end{array}$} \\
\hline and urticaria) or ifching & 1.0 & 1.7 & 1.4 & 1.6 & 2.0 \\
\hline
\end{tabular}

"Duration of treatment in "CONTROLLED STUDIES" was usually 7-14 DAYS.

"Duration of treatment in "ALL CLINICAL STUDIES" was up to 6 months.

CONTROL DRUGS: Chiorpheniramine (291 patients) patients)

In addition to the more frequent side effects reported in clinical trials (See Table), adverse effects have been reported at a lower incidence in clinical trials and/or spontaneously during marketing of Seldane that warrant listing as possibly associated with drug administration. These include: alopecia, (hair loss or thinning), anaphylaxis, angioedema, arrhythmia (including ventricular tachyarrhythmia), bronchospasm, confusion, depression, galactorrhea, hypotension, insomnia, menstrual disorders (including dysmenorrmea), musculoskeletal symptoms, nightmares, palpitation, paresthesia, photosensitivity, prolonged QT interval, seizures, sweating, syncope, tachycardia, tremor, urinary frequency, and visua dransaminase

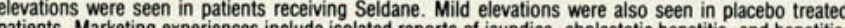
patients. Marketing experiences include isolated reports of jaundice, cholestatic hepatitis, and hepatitis in most cases available information is incomplete. In neither the clinical trials nor marketing experience a causal relationship of liver abnormalities to Seldane use clear.

OVERDOSAGE

Information concerning possible overdosage and its treatment appears in Full Prescribing Information. DOSAGE AND ADMINISTRATION

The usual dosage for adults and children 12 years and older is $60 \mathrm{mg}$ (1 tablet) twice daily. Product Information as of June, 1988 MERRELL DOW PHARMACEUTICALS INC.

Y352D

Subsidiary of The Dow Chemical Company

Merrell Dow

PRINTED IN U.S.A.

References: 1. Murphy-O'Connor JC. Renton RL, Westlake DM: Comparative trial of two dose regimens of terfenadine in patients with hay fever. J Int Med Res 1984:12:333-337. 2. Hüther KJ, Renftle G. Barraud N. et al: Inhibitory activity of terfenadine on histamine-induced skin wheals in man. Eur J Clin Pharmacol 1977:12:195-199. 3. Kemp JP. Buckley CE. Gershwin ME, et al: Multicenter, double-blind, placebo-controlled trial of terfenadine in seasonal allergic rhinitis and conjunctivitis. Ann Allergy 1985:54:502-509 4. Backhouse CI, Brewster BS. Lockhart JDF, et al: Terfenadine in allergic rhinitis. A comparative trial of a new antihistamine versus chlorpheniramine and placebo. Practitioner 1982:226:347-348, 351. 5. Buckley CE. Buchman E. Falliers CJ, et al: Terfenadine treatment of fall

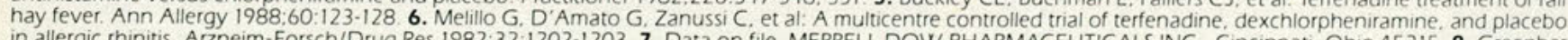

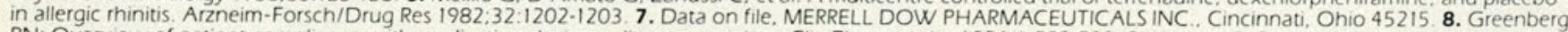
RN: Overview of patient compliance with medication dosing: a literature review. Clin Therapeutics 1984:6:592-599.9. Krause LB. Shuster S: The effect of terfenadine on dermographic wealing. Br J Dermatol 1984:10:73-79.10. Kemp JP. Falliers CJ. Fox RW. et al: A multicenter, open study of the non-sedating

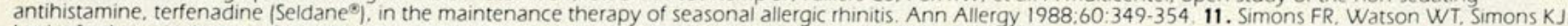
Lack of subsensitivity to terfenadine during long-term treatment. J Allergy Clin Immunol 1988:82:1068-1075 